\title{
Atrial Electromechanical Delay Is Impaired in Patients with Psoriasis
}

\author{
Bekir Calapkorur $^{\mathrm{a}}$ Saban Kelesoglu $^{\mathrm{a}}$ Bahadir Sarli $^{\mathrm{a}}$ Abdullah Turasan $^{\mathrm{b}}$ \\ Huseyin Arinc ${ }^{a}$ Mehmet Gungor Kaya ${ }^{c}$ \\ Departments of a Cardiology and ${ }^{b}$ Dermatology, Kayseri Education and Research Hospital, and \\ 'Department of Cardiology, Erciyes University, School of Medicine, Kayseri, Turkey
}

\section{Key Words}

Atrial fibrillation · Psoriasis · Atrial electromechanical delay

\begin{abstract}
Objective: In this study, we aimed to investigate atrial electromechanical delay (EMD) in patients with psoriasis. Subjects and Methods: A total of 43 patients with psoriasis ( 26 mild-moderate, 17 severe) and 17 healthy control subjects were enrolled. Patients with psoriasis were divided into two groups: the mild-moderate group and the severe group according to their psoriasis area severity index (PASI) scores. Atrial EMD was measured from the lateral mitral annulus and called 'PA lateral', from the septal mitral annulus, called 'PA septal', and from the right ventricle tricuspid annulus, called 'PA tricuspid'. Atrial EMD was defined as the time interval from the onset of atrial electrical activity ( $P$ wave on surface ECG) to the beginning of mechanical atrial contraction (late diastolic A wave). All three groups were compared with each other, and correlation analysis was performed to investigate the relationship between the PASI score and interatrial EMD. Results: PA lateral was significantly higher in both the mildmoderate psoriasis group and the severe psoriasis group compared to controls $(69 \pm 12$ and $78 \pm 13$ vs. $60 \pm 6 \mathrm{~ms} ; p=$ $0.001)$. Also, PA septal ( $63 \pm 11$ vs. $53 \pm 6 \mathrm{~ms} ; p=0.005$, post
\end{abstract}

hoc analysis) and PA tricuspid ( $49 \pm 7$ vs. $41 \pm 5 \mathrm{~ms} ; \mathrm{p}=0.009$, post hoc analysis) were significantly higher in the severe psoriasis group than in the control group. Correlation analysis revealed that the PASI score was well correlated with PA lateral $(r=0.520, p<0.001)$, PA septum $(r=0.460, p=0.002)$, interatrial EMD $(r=0.371, p=0.014)$ and intra-atrial EMD $(r=$ $0.393, p=0.009)$. Conclusion: Atrial EMD was prolonged in patients with psoriasis. The measurement of atrial EMD might be used to determine the risk of development of $A F$ in patients with psoriasis.

ㄷ) 2014 S. Karger AG, Basel

\section{Introduction}

Psoriasis is an inflammatory skin disorder which affects $2 \%$ of the general population [1]. It mainly affects the skin and joints, which may further lead to comorbidities such as metabolic syndrome, diabetes mellitus, atherosclerosis, and obesity associated with reduced exercise capacity mediated by T cells [2].

Atrial electromechanical delay (EMD) was evaluated as a noninvasive technique by tissue Doppler echocardiography (TDI) which is well correlated with cardiac arrhythmias, especially atrial fibrillation (AF) $[3,4]$. TDI

\begin{tabular}{ll}
\hline KARGER 125/s & $\begin{array}{l}\text { ( ) 2014 S. Karger AG, Basel } \\
1011-7571 / 14 / 0241-0030 \$ 39.50 / 0 \quad \text { Karger }\end{array}$ \\
$\begin{array}{l}\text { E-Mail karger@karger.com } \\
\text { www.karger.com/mpp }\end{array}$ & $\begin{array}{l}\text { This is an Open Access article licensed under the terms of the } \\
\text { Creative Commons Attribution-NonCommercial 3.0 Un- } \\
\text { ported license (CC BY-NC) (www.karger.com/OA-license), } \\
\text { applicable to the online version of the article only. Distribu- } \\
\text { tion permitted for non-commercial purposes only. }\end{array}$
\end{tabular}

Bahadir Sarli, MD

Department of Cardiology

Kayseri Education and Research Hospital

TR-38010 Kayseri (Turkey)

E-Maildrsarli@yahoo.com 
measurement of atrial EMD has been shown to correlate well with invasive measurements [3]. The prolongation of atrial EMD has been demonstrated using TDI in various diseases such as ankylosing spondylitis, systemic lupus erythematosus, type I diabetes mellitus, rheumatic mitral stenosis, familial Mediterranean fever, dilated cardiomyopathy, coronary slow flow, and sarcoidosis [5-8].

AF affects $1-2 \%$ of the general population and is associated with an increased risk of stroke, heart failure, coronary artery disease, and cardiovascular mortality [3]. Prolonged atrial EMD is associated with an increased risk of AF [9]. In addition, there is an association between AF and inflammation [9], and atrial EMD can be prolonged in psoriasis because of increased inflammation. There was no previous study which evaluated atrial EMD in psoriasis. Therefore, in this study, we evaluated atrial EMDs by using TDI in patients with different severity levels of psoriasis.

\section{Subjects and Methods}

Forty-three patients presenting with psoriasis vulgaris were consecutively included in this study; they were categorized according to disease severity using the psoriasis area severity index (PASI) [10]. Twenty-six patients (14 males and 12 females) whose PASI scores were $\leq 12$ were included in the mild-moderate severity group and 17 patients (10 males and 7 females) with PASI scores $>12$ were included in the severe disease group (10 males). Seventeen matched healthy volunteers were selected as control subjects (12 males, 5 females).

Inclusion criteria were patients $>18$ and $<70$ years old. Exclusion criteria were patients with known coronary artery disease, congestive heart failure, structural heart disease, malignancy, renal failure, and severe comorbid states. The study was approved by the Ethics Committee of our institution. Informed consent was signed by the participants.

\section{Echocardiography}

Conventional echocardiography was performed with 2-dimensional, M-mode, pulsed wave, continuous, color Doppler and tissue Doppler imaging using Philips HD11 ultrasound system (Philips, Andover, Mass., USA). Simultaneous ECG recording was done. Conventional echocardiographic images were obtained from the parasternal and apical views according to the guidelines of the American Society of Echocardiography [11]. Left ventricular (LV) diameters and wall thickness were measured from the parasternal views by M-mode echocardiography. The Teichholz method was used for the calculation of LV ejection fraction. The left atrial area and diameter were measured from the parasternal long axis view. Mitral inflow velocities were measured from apical views.

\section{Atrial Electromechanical Time Measurement}

TDI was performed using transducer frequencies of 3.5-4.0 $\mathrm{MHz}$. The spectral pulsed Doppler signal filters were adjusted un- til a Nyquist limit of $15-20 \mathrm{~cm} / \mathrm{s}$ was obtained. The minimal optimal gain was used. Myocardial TDI velocities [peak systolic ( $\left.S^{\prime}\right)$, early diastolic (E') and late diastolic velocities $\left.\left(A^{\prime}\right)\right]$ were measured with spectral pulsed Doppler from the apical 4-chamber view. The ultrasound beam slope did not exceed 15\% to acquire the optimal angle of imaging. The monitor sweep speed was adjusted at 50-100 $\mathrm{mm} / \mathrm{s}$ to optimize the spectral display of myocardial velocities. Atrial EMD was defined as the time interval from the onset of atrial electrical activity ( $\mathrm{P}$ wave on surface ECG) to the beginning of mechanical atrial contraction (late diastolic A wave). All values were averaged over 3 consecutive beats. Atrial EMD was measured from the lateral mitral annulus and called 'PA lateral', from the septal mitral annulus, called 'PA septal', and from the right ventricle tricuspid annulus, called 'PA tricuspid'. Interatrial EMD was calculated as the difference between PA lateral and PA tricuspid, intra-atrial EMD was calculated as the difference between PA septum and PA tricuspid, and left-atrial EMD was calculated as the difference between PA lateral and PA septum [12].

\section{Statistical Analysis}

The Statistical Package for Social Sciences software program (SPSS, version 16.0 for Windows) was used for statistical analysis. Continuous variables were given as means $\pm \mathrm{SD}$; categorical variables were defined as percentages. One-way analysis of variance (ANOVA) and post hoc Tukey test were used to compare the study variables among groups. The $\chi^{2}$ test was used for univariate analysis of the categorical variables. Correlation analyses were performed using Pearson's coefficient of correlation. A probability value of $p<0.05$ was considered significant, and 2 -tailed $p$ values were used for all statistics.

\section{Results}

The baseline characteristics of patients and controls are given in table 1 . There were no significant differences between groups regarding hypertension, diabetes mellitus, smoking, fasting glucose, systolic and diastolic blood pressure.

Left atrium diameter and left atrium area, LV systolic and diastolic diameters and interventricular septum, posterior wall thickness, and LV ejection fraction were similar in psoriasis patients and controls (table 2). However, PA lateral was significantly higher in both the mild-moderate and the severe psoriasis group compared to controls $(69 \pm 12$ and $78 \pm 13$ vs. $60 \pm 6 \mathrm{~ms} ; \mathrm{p}=0.001)$. Also, PA septal ( $63 \pm 11$ vs. $53 \pm 6 \mathrm{~ms} ; \mathrm{p}=0.005$, post hoc analysis) and PA tricuspid ( $49 \pm 7$ vs. $41 \pm 5 \mathrm{~ms} ; \mathrm{p}=0.009$, post hoc analysis) were significantly higher in the severe psoriasis group than in the control group. In addition, PA lateral (78 \pm 13 vs. $69 \pm 12 \mathrm{~ms} ; \mathrm{p}=0.025$, post hoc analysis) and PA septal (63 \pm 11 vs. $56 \pm 9 \mathrm{~ms} ; \mathrm{p}=0.035$, post hoc analysis) were significantly higher in patients with severe psoriasis than in those with mild-moderate psoriasis. Moreover, interatrial delay (PA lateral - PA tricuspid) was 
Table 1. Baseline demographic and laboratory properties of the control and psoriasis groups

\begin{tabular}{lcccc}
\hline & $\begin{array}{l}\text { Control } \\
\text { group } \\
(\mathrm{n}=17)\end{array}$ & $\begin{array}{l}\text { Mild-moderate } \\
\text { psoriasis group } \\
(\mathrm{n}=26)\end{array}$ & $\begin{array}{l}\text { Severe } \\
\text { psoriasis group } \\
(\mathrm{n}=17)\end{array}$ & p value \\
\hline Age, years & $45 \pm 13.5$ & $48 \pm 11$ & $47 \pm 11.5$ & 0.630 \\
Male & $12(70)$ & $14(53)$ & $10(58)$ & 0.545 \\
Hypertension & $4(23)$ & $7(26)$ & $3(17)$ & 0.781 \\
Diabetes mellitus & $2(11)$ & $3(11)$ & $2(11)$ & 0.995 \\
Smoking & $7(41)$ & $8(30)$ & $5(29)$ & 0.717 \\
Fasting glucose, mg/dl & $95.4 \pm 9.0$ & $96.0 \pm 10.8$ & $99.0 \pm 18.1$ & 0.456 \\
Systolic blood pressure, $\mathrm{mm} \mathrm{Hg}$ & $120 \pm 18$ & $115 \pm 18$ & $121 \pm 16$ & 0.451 \\
Diastolic blood pressure, $\mathrm{mm} \mathrm{Hg}$ & $78 \pm 9$ & $75 \pm 9$ & $77 \pm 7$ & 0.686 \\
PASI & N/A & $7.2 \pm 2.3$ & $16.5 \pm 3.3$ & 0.001 \\
\hline
\end{tabular}

Figures in parentheses are percentages. N/A = Not assessed.

Table 2. Echocardiographic and atrial EMD parameters of the control and psoriasis groups

\begin{tabular}{|c|c|c|c|c|}
\hline & $\begin{array}{l}\text { Control } \\
\text { group } \\
(n=17)\end{array}$ & $\begin{array}{l}\text { Mild-moderate } \\
\text { psoriasis group } \\
(n=26)\end{array}$ & $\begin{array}{l}\text { Severe } \\
\text { psoriasis group } \\
(n=17)\end{array}$ & $\mathrm{p}$ value \\
\hline LA diameter, $\mathrm{cm}$ & $3.2 \pm 0.3$ & $3.2 \pm 0.2$ & $3.4 \pm 0.2$ & 0.056 \\
\hline LA area, $\mathrm{cm}^{2}$ & $15.1 \pm 2.8$ & $15.1 \pm 2.9$ & $16.4 \pm 2.1$ & 0.277 \\
\hline LVDD, $\mathrm{cm}$ & $4.7 \pm 0.2$ & $4.6 \pm 0.4$ & $4.7 \pm 0.3$ & 0.416 \\
\hline LVSD, $\mathrm{cm}$ & $2.9 \pm 0.3$ & $3.2 \pm 0.4$ & $3.1 \pm 0.2$ & 0.126 \\
\hline IVS, cm & $1.03 \pm 0.11$ & $1.09 \pm 0.10$ & $1.08 \pm 0.10$ & 0.225 \\
\hline $\mathrm{PW}, \mathrm{cm}$ & $1.00 \pm 0.09$ & $1.04 \pm 0.08$ & $1.01 \pm 0.08$ & 0.315 \\
\hline LVEF, \% & $69 \pm 5$ & $66 \pm 6$ & $67 \pm 6$ & 0.342 \\
\hline PA lateral, ms & $60 \pm 6$ & $69 \pm 12^{\mathrm{a}, \mathrm{c}}$ & $78 \pm 13^{b}$ & 0.001 \\
\hline PA septum, ms & $53 \pm 6$ & $56 \pm 9^{c}$ & $63 \pm 11^{b}$ & 0.005 \\
\hline PA tricuspid, ms & $41 \pm 5$ & $45 \pm 10$ & $49 \pm 7^{\mathrm{b}}$ & 0.012 \\
\hline Interatrial delay, ms & $19 \pm 7$ & $23 \pm 13$ & $29 \pm 14^{b}$ & 0.056 \\
\hline Intra-atrial delay, ms & $12 \pm 7$ & $10 \pm 6$ & $14 \pm 9$ & 0.220 \\
\hline Left-atrial delay, ms & $7 \pm 5$ & $13 \pm 11$ & $15 \pm 9$ & 0.052 \\
\hline E velocity, $\mathrm{cm} / \mathrm{s}$ & $8.3 \pm 1.3$ & $7.3 \pm 1.0$ & $7.6 \pm 1.4$ & 0.030 \\
\hline A velocity, $\mathrm{cm} / \mathrm{s}$ & $6.0 \pm 1.3$ & $6.0 \pm 1.9$ & $5.9 \pm 1.9$ & 0.983 \\
\hline $\mathrm{DT}, \mathrm{ms}$ & $139 \pm 32$ & $152 \pm 29$ & $153 \pm 40$ & 0.394 \\
\hline IVRT, ms & $91 \pm 23$ & $92 \pm 26$ & $95 \pm 16$ & 0.863 \\
\hline $\mathrm{S}^{\prime}, \mathrm{cm} / \mathrm{s}$ & $10 \pm 3$ & $12 \pm 3$ & $12 \pm 4$ & 0.074 \\
\hline $\mathrm{E}^{\prime}, \mathrm{cm} / \mathrm{s}$ & $14 \pm 3$ & $13 \pm 3$ & $13 \pm 3$ & 0.259 \\
\hline $\mathrm{A}^{\prime}, \mathrm{cm} / \mathrm{s}$ & $9 \pm 3$ & $11 \pm 3$ & $9 \pm 2$ & 0.103 \\
\hline
\end{tabular}

$\mathrm{LA}=\mathrm{Left}$ atrium; $\mathrm{LVDD}=\mathrm{LV}$ end-diastolic dimension; LVSD $=\mathrm{LV}$ end-systolic dimension; IVS = interventricular septum thickness; $\mathrm{PW}=$ posterior wall thickness; $\mathrm{LVEF}=\mathrm{LV}$ ejection fraction; DT = deceleration time; IVRT = isovolumic relaxation time. Interatrial delay: PA lateral - PA tricuspid; Intra-atrial delay: PA septum PA tricuspid; Left-atrial delay: PA lateral - PA septum; $S^{\prime}$ : systolic velocity from the mitral annulus; E': early diastolic velocity from the mitral annulus; A': late diastolic velocity from the mitral annulus.

${ }^{\mathrm{a}} \mathrm{p}<0.05$ between controls and the mild-moderate psoriasis group; ${ }^{\mathrm{b}} \mathrm{p}<0.005$ between controls and the severe psoriasis group; ${ }^{\mathrm{c}} \mathrm{p}<0.005$ between the mild-moderate and the severe psoriasis group. 


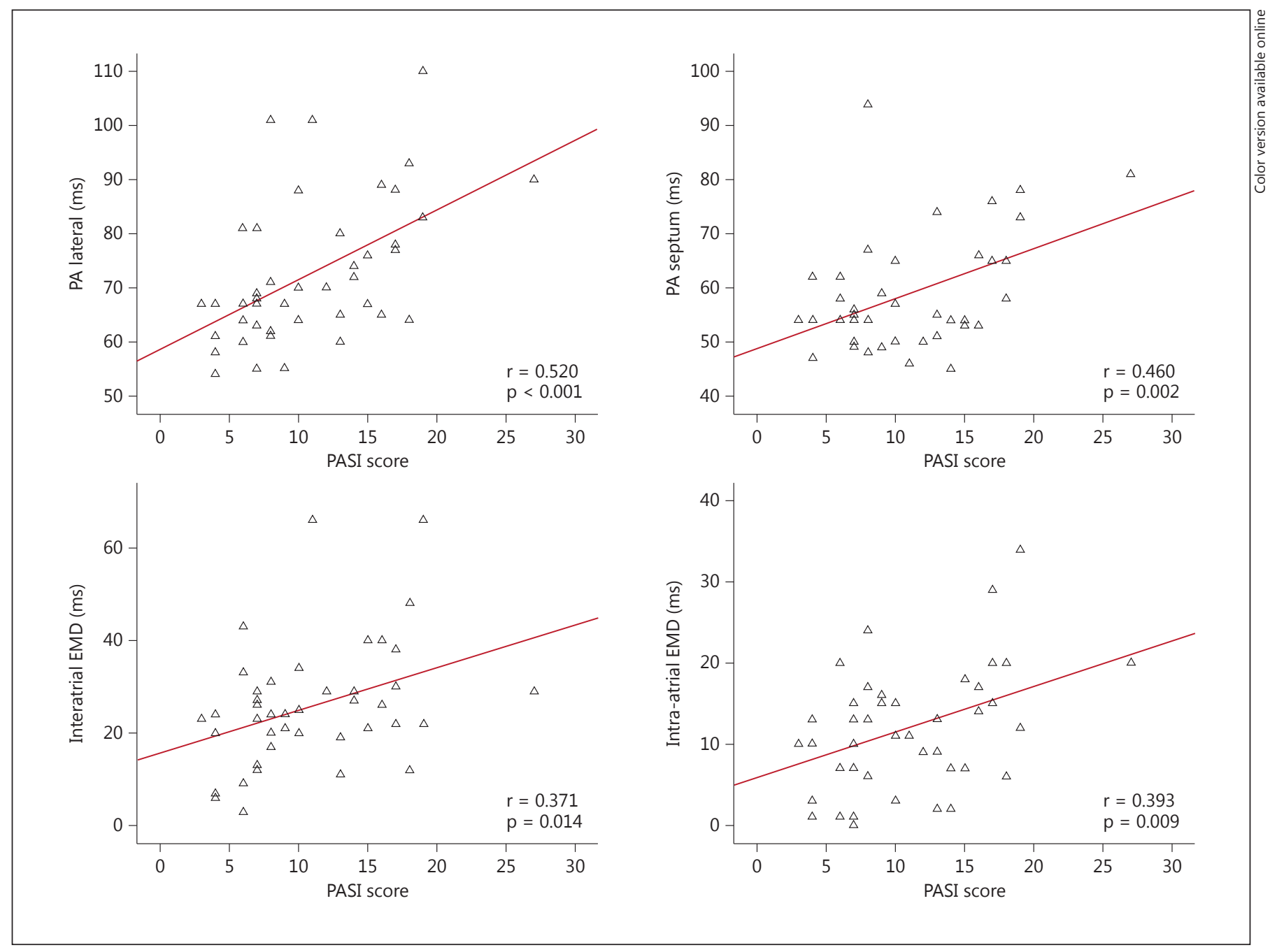

Fig. 1. Correlations between PASI score and PA lateral, PA septum, interatrial and intra-atrial EMDs.

significantly higher in the severe psoriasis group when compared with controls $(29 \pm 14$ vs. $19 \pm 7 \mathrm{~ms} ; \mathrm{p}=0.046$, post hoc analysis; table 2).

Correlation analysis revealed that the PASI score was well associated with PA lateral $(\mathrm{r}=0.520, \mathrm{p}<0.001)$, PA septum $(r=0.460, p=0.002)$, interatrial EMD $(r=0.371$, $\mathrm{p}=0.014)$ and intra-atrial EMD $(\mathrm{r}=0.393, \mathrm{p}=0.009$; fig. 1).

\section{Discussion}

In this study, we showed that atrial EMD was prolonged in patients with psoriasis. The severe psoriasis group had the most delayed atrial EMD values compared to the mild-moderate and control groups. Also, there was a significant correlation between PASI score and atrial EMD values. When taking into account that atrial EMD is a good predictor for new-onset AF, these findings suggest that psoriasis may be a risk factor for the development of AF [3, 4].

Psoriasis is a systemic inflammatory condition, with similarities to other inflammatory immune disorders. Inflammation is known as one of the precursors for the development of AF [9]. Inflammatory cells have been observed in the atria of patients with AF. Circulating levels of inflammatory markers (e.g., plasma C-reactive protein, interleukin- 6 and tumor necrosis factor- $\alpha$ ) appear to correlate with the success of electrical cardioversion and recurrence of AF following cardioversion [13]. 
Anti-inflammatory therapies like methylprednisolone and statins have been shown to decrease the risk of AF recurrences after cardioversion and of postoperative $\mathrm{AF}$ after cardiac surgery $[14,15]$. Inflammation might be a cause for the prolongation of atrial EMD in our study patients with psoriasis. When the prolongation of atrial EMD and a good correlation between PASI score and atrial EMD is considered, our findings support the fact that inflammation might be a cause for the prolongation of atrial EMD.

The prolongation of atrial conduction times in this study confirmed the previous findings of Ahlehoff et al. [16]. However, the study of Ahlehoff et al. [16] was done with a large cohort in which the groups were similar for untreated hypertension, diabetes mellitus, smoking, hyperlipidemia, and other cardiovascular risk factors.

Increased interatrial and intra-atrial EMDs, as measured by TDI, were observed in patients with paroxysmal AF compared with the control subjects [17]. We previously suggested that atrial EMD measured by TDI is a good predictor for recurrence of AF $[17,18]$. Also, prolonged atrial EMD was shown in many diseases such as sarcoidosis, systemic lupus erythematosus, diastolic dysfunction, and hypertension $[4,5,19]$, which are associated with an increased risk of AF. Several mechanisms were hypothesized to explain the relationship between prolonged atrial EMD and AF. The first is that the slowing of intra-atrial conduction is a facilitated status for initiating reentry, which caused AF or atrial flutter [20]. Another mechanism is the multiple wavelet hypothesis. Refractory period, mass and conduction velocity affect the quantity of wavelets in different parts of the atria. Hence, prolonged conduction time is related to raising the quantity of daughter wavelets and to consequences in the continuation of AF [8].

Our study showed that the duration of atrial EMD was correlated with the severity of psoriasis which may indicate the role of active inflammation in the development of rhythm disturbances. Although an increased prevalence of atherosclerotic heart diseases has been shown in patients with psoriasis, there is a lack of data regarding the association between psoriasis and rhythm disorders. Similarly to our results, Sarli et al. [21] found that heart rate recovery, which is an indicator of autonomic function, was significantly impaired in patients with psoriasis. It is well known that impaired heart recovery is associated with ventricular arrhythmia and sudden cardiac death [22]. These findings support the presence of a link between inflammation and the prolongation of atrial EMD resulting in arrhythmias.
The PASI score is the gold standard for assessing the severity of psoriasis [10]. In our study, the PASI score was well correlated with atrial EMD, thereby indicating that the mild-moderate group had a lower risk of AF than the severe group. Previously, it had been demonstrated that patients with coronary artery disease treated with statins had a lower incidence of new-onset AF [23]. The antiinflammatory effect of statins is assumed to be the mechanism that leads to decreased AF frequency [24]. Previous studies also showed that effective treatment of psoriasis and rheumatoid arthritis with anti-inflammatory agents was associated with a decrease in cardiovascular events [24]. Therefore, good control of psoriasis with anti-inflammatory treatment may help in preventing the development of AF.

The presence of prolongation of atrial EMD indicates that the measurement of atrial EMD can be a useful tool for risk stratification of AF in psoriasis patients. A recent subgroup analysis from the LIFE study demonstrating that psoriasis is independently associated with new-onset AF supports our findings [25]. This study suggested that psoriasis patients should be monitored for AF. The measurement of atrial EMD can be used to determine the high-risk population for development of AF in psoriasis.

This study had several limitations, including a relatively small sample size. Atrial EMD for the prediction of AF in patients with psoriasis was not directly investigated. Hence, long-term follow-up is needed to accurately evaluate the relationship between atrial EMD and occurrence of $\mathrm{AF}$.

\section{Conclusion}

Atrial EMD, which is an early indicator of AF development, was prolonged in patients with psoriasis. The measurement of atrial EMD might be used to determine the risk of $\mathrm{AF}$ development in psoriasis patients.

\section{Disclosure Statement}

We have no conflict of interest to disclose.
Calapkorur/Kelesoglu/Sarli/Turasan/ Arinc/Kaya 


\section{References}

1 Nestle FO, Kaplan DH, Barker, et al: Psoriasis. N Engl J Med 2009;361:496-509.

$\checkmark 2$ Reich K: The concept of psoriasis as a systemic inflammation: implications for disease management. J Eur Acad Dermatol Venereol 2012;6(suppl 2):3-11.

3 Deniz A, Sahiner L, Aytemir K, et al: Tissue Doppler echocardiography can be a useful technique to evaluate atrial conduction time. Cardiol J 2012;19:487-493.

4 Dogdu O, Yarlioglues M, Kaya MG, et al: Assessment of atrial conduction time in patients with systemic lupus erythematosus. J Invest Med 2011;59:281-286.

5 Buyukoglan H, Kaya MG, Ardic I, et al: Assessment of atrial conduction time in patients with sarcoidosis. J Invest Med 2011;59:15-21.

-6 Acar G, Akcay A, Sayarlioglu M, et al: Assessment of atrial conduction time in patients with familial Mediterranean fever. Pacing Clin Electrophysiol 2009;32:308-313.

7 Acar G, Sayarlioglu M, Akcay A, et al: Assessment of atrial electromechanical coupling characteristics in patients with ankylosing spondylitis. Echocardiography 2009;26:549557.

8 Camm AJ, Kirchhof P, Lip GY, et al: Guidelines for the management of atrial fibrillation: the Task Force for the Management of Atrial Fibrillation of the European Society of Cardiology (ESC). Europace 2010;12:1360-1420.

9 Engelmann MD, Svendsen JH: Inflammation in the genesis and perpetuation of atrial fibrillation. Eur Heart J 2005;26:2083-2092.

10 Schmitt J, Wozel G: The psoriasis area and severity index is the adequate criterion to define severity in chronic plaque-type psoriasis. Dermatology 2005;210:194-199.
11 Cheitlin MD, Armstrong WF, Aurigemma GP, et al: ACC/AHA/ASE 2003 guideline update for the clinical application of echocardiography: summary article: a report of the American College of Cardiology/American Heart Association Task Force on Practice Guidelines (ACC/AHA/ASE Committee to Update the 1997 Guidelines for the Clinical Application of Echocardiography). Circulation 2003; 108:1146-1162.

12 Ozer N, Yavuz B, Can I, et al: Doppler tissue evaluation of intra-atrial and interatrial electromechanical delay and comparison with $\mathrm{P}$ wave dispersion in patients with mitral stenosis. J Am Soc Echocardiogr 2005; 18:945-948.

13 Sata N, Hamada N, Horinouchi T, et al: Creactive protein and atrial fibrillation. Is inflammation a consequence or a cause of atrial fibrillation? Jpn Heart J 2004;45:441-445.

-14 Tveit A, Grundtvig M, Gundersen T, et al: Analysis of pravastatin to prevent recurrence of atrial fibrillation after electrical cardioversion. Am J Cardiol 2004;93:780-782.

15 Van Den Berg MP, Crijns HJ, Van Veldhuisen DJ, et al: Effects of lisinopril in patients with heart failure and chronic atrial fibrillation. J Card Fail 1995;1:355-363.

16 Ahlehoff O, Gislason GH, Jørgensen CH, et al: Psoriasis and risk of atrial fibrillation and ischaemic stroke: a Danish Nationwide Cohort Study. Eur Heart J 2012;33:2054-2064.

17 Deniz A, Yavuz B, Aytemir K, et al: Intraleft atrial mechanical delay detected by tissue Doppler echocardiography can be a useful marker for paroxysmal atrial fibrillation. Echocardiography 2009;26:779-784.
18 Rein A, O'Donnel CP, Colan SD, et al: Tissue velocity Doppler assessment of atrial and ventricular electromechanical coupling and atrioventricular time intervals in normal subjects. Am J Cardiol 2003;92:1347-1350.

19 Ermiş N, Açıkgöz N, Yaşar E, et al: Evaluation of atrial conduction time by $\mathrm{P}$-wave dispersion and tissue Doppler echocardiography in prehypertensive patients. Turk Kardiyol Dern Ars 2010;38:525-530.

20 Bayes de Luna A, Cladellas M, Oter R, et al: Interatrial conduction block and retrograde activation of the left atrium and paroxysmal supraventricular tachyarrhythmia. Eur Heart J 1988;9:1112-1118.

21 Sarli B, Dogan Y, Akpek M, et al: Heart rate recovery is impaired in patients with psoriasis. Med Princ Pract 2013;22:567-570.

22 Kaya MG, Akpek M, Lam YY, et al: Abnormal heart rate recovery on exercise in ankylosing spondylitis. Int J Cardiol 2013;169:215-218.

23 Demir K, Can I, Koc F, et al: Atorvastatin given prior to electrical cardioversion does not affect the recurrence of atrial fibrillation in patients with persistent atrial fibrillation who are on antiarrhythmic therapy. Med Princ Pract 2011;20:464-469.

24 Prodanovich S, Ma F, Taylor JR, et al: Methotrexate reduces incidence of vascular diseases in veterans with psoriasis or rheumatoid arthritis. J Am Acad Dermatol 2005;52:262267.

25 Bang CN, Okin PM, Køber L, et al: Psoriasis is associated with subsequent atrial fibrillation in hypertensive patients with left ventricular hypertrophy: the Losartan Intervention for Endpoint study. J Hypertens 2014;32:667672 